\title{
Componentes da biomassa pré-pastejo e pós-pastejo de capim-tanzânia sob lotação rotativa com quatro níveis de suplementação concentrada ${ }^{1}$
}

\section{Roberto Cláudio Fernandes Franco Pompeu², Magno José Duarte Cândido², José Neuman Miranda Neiva ${ }^{3}$, Marcos Cláudio Pinheiro Rogério ${ }^{4}$, Olivardo Facó ${ }^{5}$}

\author{
${ }^{1}$ Pesquisa financiada com recursos do convênio UFC - Banco do Nordeste/FUNDECI. \\ 2 Departamento de Zootecnia da Universidade Federal do Ceará. \\ ${ }^{3}$ Departamento de Medicina Veterinária e Zootecnia da Universidade Federal de Tocantins. \\ ${ }^{4}$ Departamento de Zootecnia da Universidade Estadual do Vale do Acaraú. \\ ${ }^{5}$ EMBRAPA/CNPC
}

RESUMO - Avaliaram-se as características estruturais do capim-tanzânia pastejado por ovinos sob lotação rotativa com quatro níveis de suplementação concentrada (NS) $(0,0 ; 0,6 ; 1,2$ e 1,8\% PV), em delineamento de parcelas subdivididas, em que as parcelas foram os níveis de suplementação e os ciclos de pastejo (CP), as subparcelas, com quatro repetições. Estimaram-se as produções de massa seca de forragem total (MSFT), forragem morta (MSFM), forragem verde (MSFV), lâmina foliar verde (MSLV) e colmo verde (MSCV), a altura (ALT) e o número de folhas/perfilho (F/P); as relações folha/colmo (F/C) e material vivo/morto (MV/MM) no pré e pós-pastejo; a densidade populacional de perfilhos (DPP); e o índice de área foliar (IAFres). Não foram observados efeitos dos NS e nem dos ciclos para as variáveis F/P, MSFM, MSFV, MV/MM, MSLV e MSCV. Para a variável ALT, observaram-se diferenças do ciclo 4 em relação aos demais. A MSFT foi afetada pelos NS, de modo que o pasto com ovinos sob suplementação a $0,6 \%$ PV foi semelhante aos dos NS de 0,0 e 1,8\% PV, porém foi superior ao do NS de $1,2 \%$ PV. Foi observado efeito dos NS sobre a MSFTres e MSFMres no nível de 0,6\% PV, sendo superior ao do nível de 1,2\% PV, porém semelhante aos demais. Para MSFVres observou-se efeito quadrático dos NS, porém não houve efeito dos CP. Para a relação MV/MMres, não foram observadas diferenças entre NS e nem entre CP. Observou-se efeito quadrático dos NS sobre a MSLVres, o IAFres e a MSCVres. Houve aumento linear na F/C com o aumento do NS. Quanto à DPP, não foi observada diferença entre NS. Os níveis crescentes de suplementação não comprometeram o vigor da rebrotação da pastagem, em razão da manutenção dos componentes da biomassa dentro de níveis aceitáveis.

Palavras-chave: altura, densidade populacional de perfilhos, índice de área foliar, massa seca de lâmina foliar verde, Panicum maximum, relação folha/colmo

\section{Pre- and post-grazing biomass components of tanzania grass under intermittent stocking with four concentrate supplementation levels}

\begin{abstract}
This research evaluated the canopy structure of tanzania grass under intermittent stocking with four concentrate supplementation levels (SL) $(0.0 ; 0.6 ; 1.2$ and, $1.8 \%$ of live weight), in a split plot design, with SL being plots and grazing cycles (GC) subplots, with four replicates. Total herbage dry mass (MSFT), death herbage dry mass (MSFM), green herbage dry mass (MSFV), green leaf blade dry mass (MSLV), green stem dry mass (MSCV), canopy height (ALT); number of live leaf per tiller (F/P), leaf/stem (F/C) and live/death material (MV/MM) ratios, pre- and post-grazing, as well as the tiller populational density (DPP) pre-grazing and residual leaf area index (IAFres) were determined. Considering pre-grazing biomass components, it was not observed significative effects between SL and GC to F/P, MSFM, MSFV, MV/MM, MSLV and, MSCV. For canopy height, it was observed difference between cycle 4 compared to others. The MSFT was affected by SL, where the sheeps supplemented with $0.6 \% \mathrm{LW}$ was similar to the ones supplemented with 0.0 and $1.8 \% \mathrm{LW}$ levels, however at the $0.6 \% \mathrm{LW}$ level, MSFT was greater than $1.2 \% \mathrm{LW}$. There were no effects of SL and cycles on MSFTres and MSFMres. It was not observed differences among 0.0, 0.6 and $1.8 \%$ SL on MSFTres and MSFMres, however the $0.6 \%$ SL (LW) was greater than $1.2 \%$ SL (LW). There was a squared effect of SL on MSFVres, however, there was no observed effect of cycles. It was not observed effect of SL and GC on the MV/ MMres relation. It was observed a squared effect of SL on the MSLVres and IAFres. There was a squared effect of SL on the MSCVres. The addition of SL caused increase in F/Cres. It was not observed effect of SL on DPP. The SL did not affect the pasture regrowth vigor, because of the maintenance of biomass components in accepted levels.
\end{abstract}

Key Words: green leaf blade dry mass, height, leaf area index, leaf/stem ratio, Panicum maximum, tiller population density 


\section{Introdução}

As pastagens constituem a principal fonte de alimento para o rebanho brasileiro de ruminantes domésticos, o que tem propiciado elevada competitividade do Brasil no mercado internacional de carne e leite, em razão do baixo custo de produção, especialmente com alimentação. $\mathrm{Na}$ produção animal em pastejo, além do valor nutritivo do pasto, a sua estrutura também afetará a resposta do animal, em termos de consumo e desempenho (Carvalho et al., 2001), além de influir na eficiência na utilização dos recursos abióticos (luz, água, nutrientes etc - Carvalho et al., 2005), interferindo, por conseguinte, no crescimento e na competição entre plantas (Lemaire, 2001).

Entre os componentes estruturais da pastagem, o tamanho da folha, a relação folha/colmo, a densidade populacional de perfilhos e o número de folhas vivas por perfilhos, aliados às características morfogênicas (alongamento de folhas e colmos, aparecimento e duração de vida das folhas), as variáveis ambientais (luz, temperatura, água e nutrientes) e o manejo adotado determinam a produtividade e a perenidade das plantas forrageiras (Cândido, 2003).

As gramíneas do gênero Panicum estão entre as principais forrageiras cultivadas no Brasil, apresentando alta produtividade e persistência sob manejo intensivo, em virtude de sua alta eficiência fotossintética e hídrica, além de ampla plasticidade fenotípica, dependendo da freqüência de desfolhação. Entretanto, graças a essa plasticidade fenotípica, estas gramíneas apresentam alterações na estrutura do dossel ao longo de seu desenvolvimento, dependendo do manejo adotado, resultando em diferentes respostas do animal às diferentes condições proporcionadas.

O manejo de pastagens visa à otimização da produção e da eficiência do uso da forragem, visando ao desempenho animal e à produtividade animal por área. A perenidade e a estabilidade da pastagem dependem da adoção de práticas racionais de manejo, entre as quais se destaca o uso de pressão de pastejo compatível com a capacidade de suporte da pastagem (Gomide \& Gomide, 2000). Uma das ferramentas para regular essa capacidade de suporte é a suplementação. O uso de suplementos tem se intensificado no Brasil, permitindo a manutenção e até melhoria da condição corporal do rebanho na época da seca e propiciando, quando do uso de suplementação concentrada, desempenho animal superior nas águas ou o ano inteiro, quando do uso de pastagens irrigadas. Neste último caso, a suplementação pode acelerar o desenvolvimento ponderal, levando os animais ao abate precocemente, como também pode proporcionar aumento da capacidade de suporte do pasto (Cardoso, 1997), maximizando o rendimento de produto animal em pequenas áreas manejadas intensivamente.

O desempenho animal em resposta aos efeitos dos níveis crescentes de suplementação tem sido bastante estudado, porém seus efeitos sobre a pastagem geralmente não são avaliados. Portanto, esta pesquisa foi conduzida com o objetivo de avaliar os componentes da biomassa pré e pós-pastejo de capim-tanzânia pastejado por ovinos sob lotação rotativa com quatro níveis de suplementação concentrada.

\section{Material e Métodos}

A pesquisa foi conduzida no Campo Avançado do Núcleo de Pesquisa em Forragicultura-NPF/DZ/CCA/UFC (www.npf.ufc.br), localizado na Fazenda Experimental Vale do Curú - FEVC/CCA/UFC, em Pentecoste/CE (entre $3^{\circ} 40^{\prime}$ a $3^{\circ} 51^{\prime} 18^{\prime \prime}$ de latitude sul e entre $39^{\circ} 10^{\prime} 19^{\prime \prime}$ e $39^{\circ} 18^{\prime} 13 \mathrm{de}$ longitude oeste), cujo clima, segundo Köeppen, é do tipo BSw'h', semi-árido quente, com precipitação média anual de $806,5 \mathrm{~mm}$, distribuída no período de janeiro a abril. O solo da área experimental é classificado como Neossolo Flúvico (solos aluviais) (Embrapa, 1999), de textura argilosa. Os dados de temperatura média, umidade relativa do ar, radiação e insolação do local no período experimental (setembro a dezembro de 2004) foram de $27,1^{\circ} \mathrm{C}, 65,5 \%, 27,3 \mathrm{MJ} / \mathrm{m}^{2}$.dia e 9,3h, respectivamente.

A área experimental, um pasto de 1,5 ha de Panicum maximum Jacq. cv. Tanzânia com topografia plana, dotada de irrigação por aspersão de baixa pressão, tem sido manejada sob lotação rotativa desde 2003 , sempre na estação seca de cada ano.

No início da pesquisa, foram colhidas três amostras de solo, que foram levadas ao Laboratório de Ciências do Solo e Água (UFC) para determinação das características físico-químicas (Tabela 1). Como foi verificado elevado nível de potássio (K), efetuou-se adubação nitrogenada, fosfatada e com micronutrientes, conforme a Comissão de Fertilidade do Solo do Estado de Minas Gerais - CFSEME (1999), tendo a uréia, o superfosfato simples e fritas como fontes desses nutrientes.

Foram avaliados quatro níveis de suplementação para ovinos pastejando capim-tanzânia sob lotação rotativa. Os níveis de suplementação corresponderam a 0,$0 ; 0,6 ; 1,2$ e 1,8\% do peso vivo (PV) dos ovinos por dia, considerando uma capacidade de consumo diária de matéria seca (MS) de 3,6\% PV, desta forma, no mais alto nível de suplementação, a proporção volumoso:concentrado da dieta foi de 50:50. 
Tabela 1 - Análise de fertilidade do solo realizada em agosto de 2004

\begin{tabular}{|c|c|c|c|c|c|c|c|c|c|c|}
\hline \multicolumn{5}{|c|}{$\left(\mathrm{mg} / \mathrm{dm}^{3}\right)$} & \multicolumn{5}{|c|}{$\left(\mathrm{cmol}_{\mathrm{c}} / \mathrm{dm}^{3}\right)$} & $\begin{array}{c}\mathrm{pH} \\
\left(\mathrm{CaCl}_{2}\right)\end{array}$ \\
\hline A & 25 & (alto) & 218 & (muito alto) & 13,8 (alto) & 6,8 & 7,0 & 0,0 & 140 & 7,7 \\
\hline $\mathrm{C}$ & 20 & (médio) & 199 & (muito alto) & 13,9 (alto) & 6,9 & 7,0 & 0,0 & 133 & 7,6 \\
\hline
\end{tabular}

O dimensionamento dos piquetes foi efetuado de modo a garantir oferta de forragem de 7,2\% PV (Hodgson, 1990), considerando-se taxa de crescimento cultural (TCC) de $140 \mathrm{~kg}$ MS/ha x dia, conforme relatado por Silva (2004).

Foram utilizados oito ovinos SRD por tratamento, resultando no total de 32 animais de prova. A escolha desses animais foi realizada por meio de sorteio.

O delineamento experimental utilizado foi o de parcelas subdivididas, em que as parcelas foram os níveis de suplementação e os ciclos de pastejo (CP), as subparcelas, com quatro repetições (piquetes amostrais) por tratamento.

A área total para cada tratamento $\left(1.472 \mathrm{~m}^{2}\right)$ foi dividida com cerca do tipo tela campestre em oito piquetes, perfazendo um total de $183,6 \mathrm{~m}^{2}$ por piquete e totalizando $5.888 \mathrm{~m}^{2}$ de área experimental (32 piquetes). O restante da área (aproximadamente $9.000 \mathrm{~m}^{2}$ ) foi utilizado como pasto de reserva, para acondicionamento dos animais de equilíbrio. Cada piquete foi provido de comedouro, bebedouro e sombrite de $8,0 \mathrm{~m}^{2}$, com $25 \%$ de transmitância de luz. O período de descanso (21 dias) correspondeu ao tempo necessário para a expansão de duas novas folhas por perfilho, conforme estimado por Silva (2004), e o período de pastejo foi de três dias, sendo usados ovinos de equilíbrio, quando necessário, para garantir o rebaixamento da vegetação para uma altura residual de $28,0 \mathrm{~cm}$, correspondente a um índice de área foliar de 1,0 (Silva, 2004), ao final do pastejo.

Durante o descanso do pasto de cada piquete, foi efetuada adubação nitrogenada em dose equivalente a $600 \mathrm{~kg}$ de N$/$ ha $x$ ano $(40 \mathrm{~kg} \mathrm{~N} / \mathrm{ha}$ x ciclo), sendo dividida em duas aplicações iguais: a primeira logo após a saída dos animais e a segunda na metade do período de descanso, tendo a área de reserva sido adubada similarmente.

A irrigação foi realizada durante a noite, visando minimizar a perda de água, especialmente pelo efeito dos ventos, assim como possíveis perdas de nitrogênio por volatilização em função das maiores temperaturas diurnas. A lâmina d'água aplicada, 11,4 mm/dia, atendeu a uma evapotranspiração da cultura de $7,97 \mathrm{~mm} /$ dia, com eficiência de aplicação de $70 \%(11,4 \mathrm{~mm} /$ dia $=7,97 \mathrm{~mm} /$ dia $\div 0,7)$ e turno de rega de quatro dias até metade do período experimental,
Tabela 2 - Composição de ingredientes utilizados na ração concentrada $(\% \mathrm{MN})$

\begin{tabular}{|c|c|}
\hline Ingrediente & $\%$ \\
\hline Milho grão & 87,50 \\
\hline Soja farelo & 5,00 \\
\hline Uréia & 3,00 \\
\hline Calcário & 1,70 \\
\hline Suplemento mineral ${ }^{1}$ & 1,50 \\
\hline Fosfato bicálcico & 0,90 \\
\hline Sal comum & 0,40 \\
\hline
\end{tabular}

${ }^{1}$ Composição: fosfato, $65,0 \mathrm{~g} ; \mathrm{Ca}, 160,0 \mathrm{~g} ; \mathrm{S}, 15,0 \mathrm{~g} ; \mathrm{Mg}, 6,5 \mathrm{~g} ; \mathrm{Na}$ 150,0 g; Co, 0,125 g; Zn, 4,5 g; Fe 1,7 g; Mn; 4,5 g; I, 0,06 g; Se, $0,03 \mathrm{~g} ; \mathrm{F}, 0,95 \mathrm{~g}$; veículo, $1000 \mathrm{~g}$.

Os ovinos do tratamento sem suplementação receberam sal mineral à vontade.

sendo de três dias daí por diante, em decorrência da redução na eficiência de irrigação.

Os animais que não receberam suplemento (nível de $0,0 \% \mathrm{PV}$, tratamento testemunha) tiveram somente sal mineral (Tabela 2) à vontade, enquanto os suplementados (níveis de 0,$6 ; 1,2$ e 1,8\% PV), concentrado uma vez ao dia (Tabela 2). O suplemento concentrado foi formulado com base no NRC (1985), considerando-se a categoria de cordeiros em terminação de $20 \mathrm{~kg}$ de peso vivo com ganhos de $250 \mathrm{~g}$ diários e crescimento moderado. Os animais de equilíbrio de cada tratamento receberam concentrado na mesma proporção, a fim de mantê-los na mesma condição dos animais dos tratamentos.

Para efeito de caracterização do alimento fornecido, foram coletadas amostras do concentrado e do capimtanzânia para realização de análises químico-bromatológicas. As amostras de capim foram coletadas no campo, levadas ao laboratório e fracionadas em material morto (MM), folha (FOL) e colmo (COL), pesadas, acondicionadas em sacos de papel perfurados e levadas à estufa de ventilação forçada a $65^{\circ} \mathrm{C}$, durante 72 horas, para proceder à pré-secagem. Em seguida, as amostras foram levadas ao Laboratório de Nutrição Animal-LNA/DZ/CCA/UFC, trituradas em moinhos tipo "Wiley", utilizando peneiras com malha de porosidade de 1,0 mm para moagem.

Nas amostras pré-secas, determinaram-se os teores de MS, matéria orgânica (MO), proteína bruta (PB), fibra em 
detergente neutro (FDN), fibra em detergente ácido (FDA), extrato etéreo (EE) e resíduo mineral (RM), conforme técnicas descritas em Silva \& Queiroz (2002). Os teores de hemiceluloses (HCEL) no material analisado, em porcentagem da MS, foram determinados por diferença, subtraindo-se da FDN a FDA, conforme descrito em Silva \& Queiroz (2002). Os teores de carboidratos totais (CHOT) foram obtidos segundo recomendações de Sniffen et al. (1992). O NDT do concentrado foi estimado conforme dados do NRC (2001). A composição químico-bromatológica da fração folha do capim-tanzânia e do suplemento concentrado pode ser visualizada na Tabela 3.

Foram avaliados quatro piquetes por tratamento. A escolha dos piquetes amostrais foi realizada por sorteio. As avaliações nos piquetes amostrais, realizadas na entrada e na saída dos animais em cada tratamento, constaram de: a) altura do dossel, amostrando-se aleatoriamente 50 pontos por piquete, com o auxílio de régua graduada; b) número de folhas vivas por perfilho - F/P (somente no pré-pastejo), efetuado contando-se o número de novas folhas expandidas, como sendo aquelas em que a lígula se encontrava exposta e contando como 0,5 folha quando a lígula ainda não estava exposta, amostrando-se 50 perfilhos aleatoriamente por piquete amostral; c) massas secas de forragem total (MSFT), forragem morta (MSFM), forragem verde (MSFV), lâmina foliar verde (MSLV) e colmo verde (MSCV), bem como relações material vivo/material morto (MV/MM) e folha/colmo (F/C), estimadas a partir do corte, em cada piquete amostral, da biomassa total de duas molduras de $1,0 \times 1,0 \mathrm{~m}$, a 5,0 cm de altura, que foram levadas ao laboratório, separando material vivo do material morto e lâminas foliares do colmo. As frações foram acondicionadas em sacos de papel perfurados, pesadas, identificadas e secas em estufa de ventilação forçada a $65^{\circ} \mathrm{C}$, por 72 horas e, em seguida, pesadas novamente; d) densidade populacional de perfilhos (DPP), estimada cinco dias após a saída dos animais dos piquetes, contando-se o número de touceiras

Tabela 3 - Composição química da fração folha do capim-tanzânia e do suplemento concentrado

\begin{tabular}{lcc}
\hline Variável (\%) & Folha & Suplemento concentrado \\
\hline MS (\%) & 22,1 & 83,3 \\
MO (\%) & 78,4 & 75,4 \\
PB (\%) & 10,1 & 20,2 \\
FDN (\%) & 71,3 & 39,1 \\
FDA (\%) & 43,0 & 3,2 \\
HCEL (\%) & 28,3 & 35,9 \\
EE (\%) & 4,1 & 3,0 \\
RM (\%) & 13,2 & 7,9 \\
CT (\%) & 72,6 & 68,9 \\
NDT $(\%)$ & - & $80,0 *$ \\
\hline
\end{tabular}

*Valor estimado conforme dados do NRC (2001). presentes em um retângulo de 2,0 x 18,0 m e, em seguida, o número de perfilhos de duas touceiras representativas da condição média naquele piquete; e) índice de área foliar residual, realizado a partir do segundo ciclo de pastejo, com o auxílio de um quadro com chapa de vidro quadriculado $\left(4,0 \mathrm{~cm}^{2}\right)$, em que as lâminas foliares residuais eram distribuídas sob a chapa de vidro e contado o número de vértices das lâminas sobrepostas pelo quadrado, por intermédio da equação:

$$
\mathrm{IAF}_{\text {res }}=\left(\mathrm{A}_{\text {ret }} \times \mathrm{M}_{\text {amostra }}\right) / \mathrm{M}_{\text {ret }} \text {, }
$$

em que $\mathrm{IAF}_{\text {res }}=$ índice de área foliar residual (adimensional); $\mathrm{A}_{\text {ret }}=$ área dos retângulos $\left(\mathrm{cm}^{2}\right) ; \mathrm{M}_{\text {amostra }}=$ massa fresca da amostra de lâminas foliares $(\mathrm{g}) ; \mathrm{M}_{\text {ret }}=$ massa fresca dos retângulos $(\mathrm{g})$.

Os dados foram analisados por meio de análise de variância, comparação de médias e análise de regressão, em que a interação níveis de suplementação $\times$ ciclos de pastejo foi desdobrada somente quando significativa a $10 \%$ de probabilidade. Para comparar o efeito dos tratamentos e ciclos, foi utilizado o teste Tukey, a $5 \%$ de probabilidade. $\mathrm{Na}$ análise de regressão, a escolha dos modelos baseou-se na significância dos coeficientes linear e quadrático, utilizando-se o teste " $\mathrm{t}$ ", de Student, a $10 \%$ de probabilidade. Como ferramenta de auxílio às análises estatísticas, utilizaram-se os procedimentos MIXED e GLM (SAS, 1999).

\section{Resultados e Discussão}

Não foi observada interação $(\mathrm{P}>0,10)$ níveis de suplementação $\times$ ciclos de pastejo para altura média (ALT), número de folhas vivas por perfilhos (F/P), massas secas de forragem total (MSFT), forragem morta (MSFM), forragem verde (MSFV), lâminas foliares verdes (MSLV) e colmos verdes (MSCV), assim como relações material vivo/material morto (MV/MM) e folha/colmo (F/C) dos componentes da biomassa pré-pastejo. Dessa forma, os fatores foram analisados somente para o efeito principal (Tabelas 4 e 5).

Não houve efeito $(\mathrm{P}>0,10)$ dos níveis de suplementação, nem entre níveis de suplementação $(\mathrm{P}>0,05)$, sobre a altura do pasto (ALT), com média de 55,67 cm (Tabela 4). A altura do pasto é conseqüência do tempo de rebrotação da gramínea e de suas adaptações morfológicas durante esse processo (Cândido, 2003). Quanto ao efeito de ciclos, observaram-se diferenças $(\mathrm{P}<0,05)$ do ciclo $4(60,08 \mathrm{~cm}) \mathrm{em}$ relação aos demais, estes com média de $54,20 \mathrm{~cm}$ (Tabela 5). A maior altura no ciclo 4 em relação às demais foi, possivelmente, decorrente do aumento no comprimento do pseudocolmo $(16,48 ; 18,09 ; 18,53$ e 20,40 cm - ciclos 1,2 , 3 e 4, respectivamente), no decorrer dos ciclos (dados não apresentados). 
Tabela 4 - Componentes da biomassa pré-pastejo do capim-tanzânia sob lotação rotativa com quatro níveis de suplementação concentrada

\begin{tabular}{lrrrrr}
\hline \multirow{2}{*}{ Item } & \multicolumn{4}{c}{ Nível de suplementação $(\%)$} & \multicolumn{2}{c}{ Regressão } & \\
\cline { 2 - 4 } & \multicolumn{1}{c}{0,0} & 0,6 & 1,2 & 1,8 & \\
\hline ALT (cm) & $56,80 \mathrm{a}$ & $56,35 \mathrm{a}$ & $54,01 \mathrm{a}$ & $55,52 \mathrm{a}$ & $\hat{\mathrm{Y}}=55,67 \pm 3,62$ \\
F/P & $1,80 \mathrm{a}$ & $1,77 \mathrm{a}$ & $1,82 \mathrm{a}$ & $1,84 \mathrm{a}$ & $\hat{\mathrm{Y}}=1,81 \pm 0,06$ \\
MSFT (kg/ha) & $7.445 \mathrm{ab}$ & $8.487 \mathrm{a}$ & $6.469 \mathrm{~b}$ & $7.522 \mathrm{ab}$ & $\hat{\mathrm{Y}}=7481 \pm 1116$ \\
MSFM (kg/ha) & $2.176 \mathrm{a}$ & $2.662 \mathrm{a}$ & $1.885 \mathrm{a}$ & $2.644 \mathrm{a}$ & $\hat{\mathrm{Y}}=2342 \pm 574$ \\
MSFV (kg/ha) & $4.995 \mathrm{a}$ & $4.898 \mathrm{a}$ & $4.584 \mathrm{a}$ & $4.889 \mathrm{a}$ & $\hat{\mathrm{Y}}=4841 \pm 551$ \\
MV/MM & $2,44 \mathrm{a}$ & $1,66 \mathrm{a}$ & $2,54 \mathrm{a}$ & $2,03 \mathrm{a}$ & $\hat{\mathrm{Y}}=2,17 \pm 0,64$ \\
MSLV (kg/ha) & $3.091 \mathrm{a}$ & $2.727 \mathrm{a}$ & $2.987 \mathrm{a}$ & $2.947 \mathrm{a}$ & $\hat{Y}=2938 \pm 275$ \\
MSCV (kg/ha) & $1.884 \mathrm{a}$ & $2.057 \mathrm{a}$ & $1.597 \mathrm{a}$ & $1.942 \mathrm{a}$ & $\hat{Y}=1870 \pm 332$ \\
F/C & $1,55 \mathrm{ab}$ & $1,26 \mathrm{~b}$ & $1,93 \mathrm{a}$ & $1,59 \mathrm{ab}$ & $\hat{\mathrm{Y}}=1,58 \pm 0,32$ \\
\hline
\end{tabular}

Altura média do dossel (ALT), número de folhas vivas por perfilhos (F/P), massa seca de forragem total (MSFT), de forragem morta (MSFM), de forragem verde (MSFV), de lâminas foliares verdes (MSLV), de colmos verdes (MSCV), assim como as relações material vivo/material morto (MV/MM) e folha/colmo $(\mathrm{F} / \mathrm{C})$.

Modelo da equação de regressão escolhido com base na significância dos coeficientes linear e quadrático, utilizando-se o teste "t", de Student, a 10\% de probabilidade.

Tabela 5 - Efeito dos ciclos de pastejo sobre os componentes da biomassa pré-pastejo de capim-tanzânia sob lotação rotativa com quatro níveis de suplementação concentrada

\begin{tabular}{|c|c|c|c|c|c|c|}
\hline \multirow[t]{2}{*}{ Item } & \multicolumn{4}{|c|}{ Ciclo de pastejo } & \multirow[t]{2}{*}{ Média } & \multirow[t]{2}{*}{$\mathrm{CV}(\%)$} \\
\hline & 1 & 2 & 3 & 4 & & \\
\hline $\mathrm{ALT}(\mathrm{cm})$ & $55,73 b$ & $52,06 \mathrm{~b}$ & $54,81 b$ & $60,08 \mathrm{a}$ & 55,67 & 6,63 \\
\hline $\mathrm{F} / \mathrm{P}$ & $1,80 \mathrm{a}$ & $1,75 \mathrm{a}$ & $1,81 \mathrm{a}$ & $1,86 \mathrm{a}$ & 1,81 & 3,26 \\
\hline MSFT (kg/ha) & $7.564 \mathrm{a}$ & $7.378 \mathrm{a}$ & $7.093 \mathrm{a}$ & $7.889 a$ & 7.481 & 11,37 \\
\hline MSFM (kg/ha) & $2.253 \mathrm{a}$ & $2.534 \mathrm{a}$ & $2.238 \mathrm{a}$ & $2.343 \mathrm{a}$ & 2.342 & 20,34 \\
\hline MSFV (kg/ha) & $4.589 b$ & $4.496 b$ & $4.693 b$ & $5.586 \mathrm{a}$ & 4.841 & 11,39 \\
\hline $\mathrm{MV} / \mathrm{MM}$ & $1,96 \mathrm{a}$ & $1,96 \mathrm{a}$ & $2,39 \mathrm{a}$ & $2,38 \mathrm{a}$ & 2,17 & 24,86 \\
\hline MSLV (kg/ha) & $2.664 b$ & $2.661 b$ & $3.013 \mathrm{ab}$ & $3.414 \mathrm{a}$ & 2.938 & 8,88 \\
\hline MSCV (kg/ha) & $1.832 \mathrm{a}$ & $1.830 \mathrm{a}$ & $1732 \mathrm{a}$ & $2.087 \mathrm{a}$ & 1.870 & 14,93 \\
\hline $\mathrm{F} / \mathrm{C}$ & $1,44 \mathrm{a}$ & $1,53 \mathrm{a}$ & $1,73 \mathrm{a}$ & $1,63 \mathrm{a}$ & 1,58 & 13,30 \\
\hline
\end{tabular}

Altura média do dossel (ALT), número de folhas vivas por perfilhos (F/P), massa seca de forragem total (MSFT), de forragem morta (MSFM), de forragem verde (MSFV), de lâminas foliares verdes (MSLV), de colmos verdes (MSCV), assim como as relações material vivo/material morto (MV/MM) e folha/colmo $(\mathrm{F} / \mathrm{C})$.

Médias na mesma linha, seguidas de letras iguais, não diferem $(P>0,05)$ pelo teste Tukey.

Apesar de a freqüência de pastejo ter sido de 21 dias, não foi suficiente para controlar a altura do dossel no último ciclo, comportamento também relatado por Uebele (2002) e Cândido (2003). Silva (2004), trabalhando com capim-tanzânia sob três períodos de descansos, observou que, no período de descanso sob 2,5 folhas por perfilhos, a altura do pasto variou entre $50,0 \mathrm{~cm}$ (ciclo 1) e $74,7 \mathrm{~cm}$ (ciclo 4), em decorrência do aumento do comprimento das lâminas foliares e dos pseudocolmos no decorrer dos ciclos. Dessa forma, a altura do pasto pode comprometer a qualidade da forragem, em razão da maior dificuldade do animal de apreender a forragem dispersa em um horizonte de pastejo mais amplo (Carvalho et al., 2006).

Não houve efeito dos níveis de suplementação $(P>0,10)$, nem entre níveis de suplementação $(\mathrm{P}>0,05)$ e nem entre ciclos de pastejo $(\mathrm{P}>0,05)$ sobre o número de folhas vivas por perfilho (F/P), com média de 1,81 F/P (Tabelas 4 e 5), porém inferior ao recomendado por Silva (2004), de 2,0 F/P, para o período de descanso de 21 dias. Este fato decorreu de problemas com excesso de água dentro da pastagem em alguns momentos, devido ao arrombamento de canais de irrigação adjacentes à área experimental, o que também comprometeu o calendário das adubações. Como conseqüência, houve redução na taxa de aparecimento e de alongamento foliar, comprometendo o F/P preconizado. Anslow (1966) comentou que menor disponibilidade de nutrientes na região do meristema apical compromete o aparecimento de novas folhas.

$\mathrm{Na}$ análise de regressão, não se observou efeito $(\mathrm{P}>0,10)$ dos níveis de suplementação sobre a massa seca de forragem total (MSFT). Na comparação de médias, a MSFT do pasto com ovinos suplementados no nível de $0,6 \% \mathrm{PV}$, com $8.487 \mathrm{~kg} / \mathrm{ha}$, foi semelhante $(\mathrm{P}>0,05)$ àquelas dos níveis de 0,0 e $1,8 \% \mathrm{PV}$, porém superior $(\mathrm{P}<0,05)$ àquela do 
nível de 1,2\% PV, com $6.469 \mathrm{~kg} / \mathrm{ha}$ (Tabela 4). Essa ocorrência pode definir tendência $(\mathrm{P} \leq 0,28)$ de menor massa seca de forragem morta (MSFM) do nível de 1,2\% $\mathrm{PV}$, com média de $1.885 \mathrm{~kg} / \mathrm{ha}$ em relação aos demais (média de $2.494 \mathrm{~kg} / \mathrm{ha}$ ), demonstrando a possível ocorrência de efeito aditivo, com animais exercendo maior intensidade de pastejo sobre a estrutura do pasto até o nível de 1,2\% de suplementação e, em seguida, efeito substitutivo, reduzindo a intensidade de pastejo.

Não houve efeito dos níveis de suplementação $(\mathrm{P}>0,10)$ entre níveis de suplementação $(\mathrm{P}>0,05)$, nem entre ciclos de pastejo $(\mathrm{P}>0,05)$ sobre a MSFT e MSFM, com média de 7.481 e $2.342 \mathrm{~kg} / \mathrm{ha}$, respectivamente (Tabelas 4 e 5). A MSFT foi superior àquela relatada por Canto et al. (2002), trabalhando com capim-tanzânia no Noroeste do Paraná com diferentes alturas, obtendo MSFT de $4.007 \mathrm{~kg} / \mathrm{ha}$, com 55,8 cm de altura. Costa et al. (1992), por sua vez, citaram MSFT de 6.379 e $6.791 \mathrm{~kg} / \mathrm{ha}$, respectivamente, para os capins colonião e tobiatã sob diferentes manejos em São Paulo, com doses nitrogenadas equivalentes a $650 \mathrm{~kg} / \mathrm{ha} \mathrm{x}$ ano.

A MSFM $(2.342 \mathrm{~kg} / \mathrm{ha})$ observada nesta pesquisa foi inferior à relatada por Canto et al. (2001), avaliando capimtanzânia com diferentes alturas, estimando-se MSFM de $2.855 \mathrm{~kg} / \mathrm{ha}$, com 55,67 cm de altura, e superior à verificada por Silva (2004), de $662 \mathrm{~kg} / \mathrm{ha}$, trabalhando com capimtanzânia, com período de descanso de 2,5 F/P. A maior MSFM deste experimento em relação à Silva (2004) é atribuída ao fato de a altura do corte para a amostragem de forragem ter sido realizada a $5,0 \mathrm{~cm}$, enquanto a obtida por esse autor foi a $15,0 \mathrm{~cm}$. Soma-se a isto a grande quantidade de material morto proveniente da roçada de uniformização feita antes de se iniciar o experimento. Este acúmulo de MSFM pode ser atribuído também ao sombreamento mútuo pelas folhas mais altas, diminuindo a capacidade fotossintética das folhas dos estratos inferiores da vegetação, antecipando sua senescência (Gomide, 1973).

Não houve efeito do nível de suplementação $(\mathrm{P}>0,10)$, nem entre níveis de suplementação $(\mathrm{P}>0,05)$, sobre a massa seca de forragem verde (MSFV) do pasto, com média de $4.841 \mathrm{~kg} / \mathrm{ha}$ (Tabela 4), estando acima dos $2.000 \mathrm{~kg} / \mathrm{ha}$ preconizados por Minson (1990) para não ocorrer redução na ingestão de MS, devido à diminuição do tamanho do bocado e ao aumento do tempo de pastejo. Entretanto, a elevada massa de colmo (um dos componentes da MSFV) pode reduzir o consumo voluntário de MS, em virtude do elevado conteúdo de carboidratos fibrosos desta fração. Brâncio et al. (2003), trabalhando com três cultivares do gênero Panicum, obtiveram produções de MSFV próximas de $3.525,2.290$ e $4.000 \mathrm{~kg} / \mathrm{ha}$ para os cultivares Tanzânia, Mombaça e Massai, respectivamente, com período de des- canso de 35 dias, sendo inferiores aos valores obtidos neste experimento. Cecato et al. (2000), trabalhando com gramíneas do gênero Panicum sob duas alturas de corte, relataram produções de 1.499, 4.294, 2.759, 5.286, $4.141 \mathrm{e}$ $4.773 \mathrm{~kg} / \mathrm{ha}$ para os cultivares Aruana, Centenário, Colonião, Mombaça, Tanzânia e Tobiatã, respectivamente, com período de descanso de 35 dias.

Quanto ao efeito de ciclos sobre a MSFV, observou-se diferença $(\mathrm{P}<0,05)$ do ciclo $4(5.586 \mathrm{~kg} / \mathrm{ha})$ em relação aos demais, cuja média foi de $4.593 \mathrm{~kg} / \mathrm{ha}$ (Tabela 5), justificada por aumentos de 22,8 e de $16,1 \%$ de massa seca de lâminas foliares verdes (MSLV) e de colmos verdes (MSCV), respectivamente, do ciclo 4 em relação aos demais. $O$ aumento da MSFV no decorrer dos ciclos de pastejo também foi relatado por Cândido (2003), trabalhando com capimmombaça com período de descanso de $2,5 \mathrm{~F} / \mathrm{P}$, porém afirmando que a maior MSFV do ciclo $3(4.447 \mathrm{~kg} / \mathrm{ha}) \mathrm{em}$ relação aos demais $(3.632 \mathrm{~kg} / \mathrm{ha})$ deveu-se principalmente ao crescimento dos colmos, visto que não foram verificadas diferenças na MSLV, o que não foi verificado $(P>0,05)$ neste experimento, embora tenha havido acréscimo de 13,92\% na MSCV do ciclo 1 para o 4. De fato, o autor afirma que o alongamento dos colmos é importante componente do processo de produção de forragem nas gramíneas do tipo $\mathrm{C}_{4}$ a partir de certo tempo de rebrotação, pela sua ocorrência ainda na fase vegetativa.

Para a relação material vivo/material morto (MV/MM), não houve efeito $(\mathrm{P}>0,10)$ dos níveis de suplementação, assim como não houve diferença entre níveis de suplementação $(\mathrm{P}>0,05)$ e entre ciclos $(\mathrm{P}>0,05)$, com média de 2,17 (Tabelas 4 e 5). Observa-se que a relação MV/MM neste experimento foi inferior àquela obtida por Silva (2004), trabalhando com capim-tanzânia sob três períodos de descansos (1,5; 2,5 e 3,5 F/P), com médias de 7,70; 7,95 e 4,44, respectivamente. Vale ressaltar que a altura de corte do capim amostrado do referido autor era de $15,0 \mathrm{~cm}$.

Não houve efeito $(\mathrm{P}>0,10)$ do nível de suplementação, nem diferença entre níveis de suplementação $(\mathrm{P}>0,05)$ sobre a massa seca de lâminas foliares verdes (MSLV) do pasto, com média de $2.938 \mathrm{~kg} / \mathrm{ha}$ (Tabela 4). Porém, quanto ao efeito de ciclos (Tabela 5), não foram observadas diferenças $(\mathrm{P}>0,05)$ entre os ciclos 3 e 4 , com 3.013 e $3.414 \mathrm{~kg} / \mathrm{ha}$, respectivamente, sendo o último superior $(\mathrm{P}<0,05)$ aos demais.

A MSLV é uma variável estrutural de grande importância para o desempenho animal, uma vez que é a fração mais selecionada pelos ruminantes em pastejo. Assim, Nabinger (2002) afirmou que a utilização da massa de forragem produzida deve ocorrer antes do alcance do IAF crítico, ou seja, antes que seja desencadeado o processo de senescência. 
A MSLV deste experimento foi superior à relatada por Silva (2004), trabalhando com capim-tanzânia sob lotação rotativa com PD de 2,5 F/Pe adubado com $600 \mathrm{~kg}$ de N/ha $\mathrm{x}$ ano, que obteve produção de $2.859 \mathrm{~kg} / \mathrm{ha}$.

Considerando a produção anual, observou-se neste experimento produção de MSLV de $44.682 \mathrm{~kg} / \mathrm{ha}$ x ano, (365 dias $\div 24$ dias/ciclo $\times 2.938 \mathrm{~kg} \mathrm{MSLV/ciclo)} \mathrm{versus}$ $40.136 \mathrm{~kg} \mathrm{MSLV} / \mathrm{hax}$ ano (365 dias $\div 26$ dias PD) $\mathrm{x} 2.859 \mathrm{~kg}$ MSLV/ciclo (Silva, 2004). Vale destacar que esse autor trabalhou com IAF residual de 1,00, sendo inferior ao IAF residual médio obtido nesta pesquisa, de 2,20, apesar de a altura residual estipulada pelo referido autor, de $28,0 \mathrm{~cm}$, ter sido adotada neste experimento. Assim, é possível que esse maior IAF residual tenha propiciado a recuperação mais rápida da gramínea, não havendo possivelmente mobilização de reservas orgânicas para o restabelecimento do dossel (Brougham, 1956).

Considerando-se UA de $450 \mathrm{~kg}$ PV, observa-se que a pastagem manejada com os ovinos não-suplementados neste experimento foi capaz de manter 7,50 UA/ha (dados não apresentados), ofertando cerca de 41,56 kg MSFT/UA $\mathrm{x} \operatorname{dia}(7.481 \mathrm{~kg} \mathrm{MSFT} /$ ciclo $\div$ 7,50 UA/ha $\div 24$ dias), totalizando eficiência de uso da forragem de $38 \%(15,75 \mathrm{~kg}$ MS consumida/UA x dia $\div 41,56 \mathrm{~kg}$ MSFT/UA x dia), o que está dentro do limite da faixa de oferta de forragem de duas a três vezes a capacidade de consumo diário dos ruminantes em pastejo, definida por Hodgson (1990) como necessária para garantir o máximo desempenho individual do animal.

Canto et al. (2001), trabalhando com capim-tanzânia com diferentes alturas de corte durante o inverno, relataram MSLV de $1.347 \mathrm{~kg} / \mathrm{ha}$ com o capim medindo $55,8 \mathrm{~cm}$ de altura, sendo capaz de manter 3,0 UA/ha. Cecato et al. (2000) observaram MSLV de 936; 3.360; 2.179; 4.131; 3.388 e $3.751 \mathrm{~kg} / \mathrm{ha}$ para os cultivares Aruana, Centenário, Colonião, Mombaça, Tanzânia e Tobiatã, respectivamente, após corte a $20 \mathrm{~cm}$ de altura a cada 35 dias, obtendo taxas de lotação na ordem de 2,08; 7,47; 4,84; 9,18; 7,53 e 8,33 UA/ha.

Quanto à massa seca de colmo verde (MSCV), não foi observado efeito $(\mathrm{P}>0,10)$ dos níveis de suplementação, assim como não houve diferença $(\mathrm{P}>0,05)$ entre níveis de suplementação e entre ciclos ( $\mathrm{P}>0,05)$, com MSCV média de $1.870 \mathrm{~kg} / \mathrm{ha}$ (Tabelas 4 e 5), sendo superior aos obtidos por Silva (2004), de $659 \mathrm{~kg} / \mathrm{ha}$, e Canto et al. (2001), de $750 \mathrm{~kg} / \mathrm{ha}$, trabalhando com capim-tanzânia de 64,0 e $55,8 \mathrm{~cm}$, respectivamente. A maior MSCV obtida neste experimento em relação àquelas dos referidos autores deveu-se à menor altura de corte do capim amostrado $(5,0 \mathrm{~cm})$.

Apesar de não ter havido diferenças $(\mathrm{P}>0,05)$ entre ciclos, observou-se tendência $(P \leq 0,19)$ na elevação de massa de colmo no último ciclo de pastejo, com produção média de $2.087 \mathrm{~kg} / \mathrm{ha}$ em relação aos três primeiros ciclos, com MSCV média de $1.798 \mathrm{~kg} / \mathrm{ha}$. O mesmo comportamento foi relatado por Cândido (2003), trabalhando com o cultivar Mombaça sob período de descanso de 2,5; 3,5 e 4,5 folhas por perfilhos, com a MSCV aumentando progressivamente no decorrer dos ciclos. Isto se deve ao fato de a taxa de alongamento das hastes (TAlH) $(0,09$ e $0,13 \mathrm{~cm} /$ perfilho $\mathrm{x}$ dia-ciclos 1 e 4 , respectivamente) e a altura do pseudocolmo (16,48 e 20,40 cm-ciclos 1 e 4, respectivamente) elevarem-se progressivamente com os ciclos de pastejo (dados não apresentados), frações rejeitadas em decorrência da seletividade do animal em pastejo.

$\mathrm{Na}$ comparação de médias, a relação folha/colmo (F/C) do pasto com os ovinos suplementados a $1,2 \% \mathrm{PV}(1,93)$ foi semelhante $(\mathrm{P}>0,05)$ às dos níveis de 0,0 e 1,8\% PV, com médias de F/C de 1,55 e 1,59, respectivamente, porém o pasto do nível de suplementação de 1,2\% PV foi superior $(\mathrm{P}<0,05)$ no nível de $0,6 \%$ PV, com média de F/C de 1,26 (Tabela 4). A relação folha/colmo(F/C) é uma variável de grande importância para nutrição animal e o manejo das plantas forrageiras, pois está associada à facilidade com que os animais colhem a forragem preferida (folhas) (Brâncio et al., 2003). Tem-se considerado o valor de 1,0 como limite crítico para esta relação (Pinto et al., 1994), sendo que valores inferiores implicariam em queda na qualidade da forragem produzida. Portanto, os valores obtidos no pré-pastejo não estariam limitando o consumo dos animais em pastejo.

$\mathrm{Na}$ análise de regressão, não foi observado efeito $(\mathrm{P}>0,10)$ dos níveis de suplementação sobre a relação $\mathrm{F} / \mathrm{C}$ do pasto (Tabela 4), assim como não houve diferença entre os ciclos de pastejo $(\mathrm{P}>0,05)$ para a variável $\mathrm{F} / \mathrm{C}$, com média de 1,58 (Tabela 5). É possível que a freqüência de desfolhação de 21 dias, com altura residual de $28,0 \mathrm{~cm}$, tenha controlado as características estruturais do pasto.

Tendo sido efetuada a análise de variância, não foi observada interação $(\mathrm{P}>0,10)$ de níveis de suplementação $\times$ ciclos de pastejo para altura média residual (ALTres), massas seca de forragem total (MSFTres), forragem morta (MSFMres), forragem verde (MSFVres), lâminas foliares verdes (MSLVres) e colmos verdes (MSCVres), assim como relações material vivo/material morto (MV/MMres) e folha/ colmo (F/Cres), densidade populacional de perfilhos (DPP) e índice de área foliar residual (IAFres) das características estruturais do resíduo pós-pastejo (Tabelas 6 e 7). Dessa forma, os fatores foram analisados somente para o efeito principal.

Não houve efeito $(\mathrm{P}>0,10)$ dos níveis de suplementação, nem entre níveis de suplementação $(\mathrm{P}>0,05)$ sobre a altura residual do pasto (ALTres), com média de $28,42 \mathrm{~cm}$ 
(Tabela 6), sendo próxima à altura residual preconizada $(28,0 \mathrm{~cm})$ para um período de descanso de 21 dias, conforme estipulado por Silva (2004), trabalhando com ovinos pastejando o capim-tanzânia sob lotação rotativa. Quanto ao efeito de ciclos de pastejo, não se observaram diferenças $(\mathrm{P}>0,05)$ no decorrer dos ciclos, comprovando acurácia na manutenção da altura residual preconizada (Tabela 7).

Para a massa seca de forragem total residual (MSFTres), não foi observado efeito $(\mathrm{P}>0,10)$ dos níveis de suplementação, com média de $6.121 \mathrm{~kg} /$ ha (Tabela 6). Na comparação de médias dos níveis de suplementação sobre a MSFTres (Tabela 6), observou-se que, no pasto dos ovinos suplementados com o nível de 0,6\% PV (7.219 kg/ha), essa variável foi superior $(\mathrm{P}<0,05)$ àquela do nível de 1,2\% PV (4.476 kg/ha), porém semelhante $(\mathrm{P}>0,05)$ aos demais. O mesmo ocorreu com a massa seca de forragem morta residual (MSFMres), em que o pasto dos ovinos sob suplementação no nível de $0,6 \% \mathrm{PV}(2.746 \mathrm{~kg} / \mathrm{ha})$ foi superior $(\mathrm{P}<0,05)$ ao nível de $1,2 \%$ $\mathrm{PV}(1.830 \mathrm{~kg} / \mathrm{ha})$, porém semelhante $(\mathrm{P}>0,05)$ aos demais (Tabela 6).

Não houve efeito dos ciclos de pastejo $(\mathrm{P}>0,05)$ sobre as variáveis MSFTres e MSFMres, com médias de 6.121 e $2.326 \mathrm{~kg} / \mathrm{ha}$, respectivamente (Tabela 7). A superioridade destes valores em relação aos obtidos por Silva (2004), que, trabalhando com capim-tanzânia sob período de descanso de 2,5 F/P, observou MSFT e MSFM residual de $1.788 \mathrm{e} 458 \mathrm{~kg} / \mathrm{ha}$, respectivamente, pode ser explicada pela menor altura de amostragem da forragem nesta pesquisa,

Tabela 6 - Componentes da biomassa pós-pastejo do capim-tanzânia sob lotação rotativa com quatro níveis de suplementação concentrada

\begin{tabular}{|c|c|c|c|c|c|c|}
\hline \multirow[t]{2}{*}{ Item } & \multicolumn{4}{|c|}{ Nível de suplementação (\%) } & \multirow[t]{2}{*}{ Regressão } & \multirow[t]{2}{*}{$\mathrm{CV}(\%)$} \\
\hline & 0,0 & 0,6 & 1,2 & 1,8 & & \\
\hline ALTres $(\mathrm{cm})$ & $28,36 \mathrm{a}$ & $28,27 \mathrm{a}$ & $28,62 \mathrm{a}$ & $28,43 \mathrm{a}$ & $\hat{\mathrm{Y}}=28,42 \pm 0,30$ & 1,02 \\
\hline MSFTres (kg/ha) & $6.377 \mathrm{ab}$ & $7.219 \mathrm{a}$ & $4.476 b$ & $6.114 \mathrm{ab}$ & $\hat{\mathrm{Y}}=6121 \pm 1209$ & 19,16 \\
\hline MSFMres (kg/ha) & $2.401 \mathrm{ab}$ & $2.746 \mathrm{a}$ & $1.830 \mathrm{~b}$ & $2.327 \mathrm{ab}$ & $\hat{\mathrm{Y}}=2326 \pm 378$ & 24,67 \\
\hline MSFVres (kg/ha) & $3727 \mathrm{a}$ & $3.453 \mathrm{ab}$ & $3.065 b$ & $3.614 \mathrm{ab}$ & $\hat{Y}=3779-1150 x+572 x^{2} ; R^{2}=0,36$ & 9,40 \\
\hline MV/MMres & $1,70 \mathrm{ab}$ & $1,12 \mathrm{~b}$ & $1,94 \mathrm{a}$ & $1,68 \mathrm{ab}$ & $\hat{\mathrm{Y}}=1,61 \pm 0,42$ & 25,60 \\
\hline MSLVres (kg/ha) & $1.461 \mathrm{ab}$ & $1.273 b$ & $1.534 \mathrm{a}$ & $1605 \mathrm{a}$ & $\hat{Y}=1429-209 x+180 x^{2} ; R^{2}=0,38$ & 9,76 \\
\hline IAFres & $2,07 \mathrm{~b}$ & $1,81 \mathrm{~b}$ & $2,23 \mathrm{ab}$ & $2,70 \mathrm{a}$ & $\hat{\mathrm{Y}}=2,03-0,52 \mathrm{x}+0,50 \mathrm{x}^{2} ; \mathrm{R}^{2}=0,62$ & 12,32 \\
\hline MSCVres (kg/ha) & $2.228 \mathrm{a}$ & $2.178 \mathrm{a}$ & $1.531 \mathrm{~b}$ & $2.007 \mathrm{ab}$ & $\hat{Y}=2314-876 x+365 x^{2} ; \quad R^{2}=0,31$ & 16,46 \\
\hline $\mathrm{F} / \mathrm{Cres}$ & $0,69 \mathrm{c}$ & $0,61 \mathrm{c}$ & $1,05 \mathrm{a}$ & $0,85 b$ & $\hat{\mathrm{Y}}=0,80 \pm 0,24$ & 19,93 \\
\hline DPP (perfilhos $/ \mathrm{m}^{2}$ ) & $534 \mathrm{a}$ & $578 \mathrm{a}$ & $548 \mathrm{a}$ & $533 a$ & $\hat{Y}=548 \pm 58,0$ & 10,35 \\
\hline
\end{tabular}

Altura média residual (ALTres), massas secas de forragem total (MSFTres), forragem morta (MSFMres), forragem verde (MSFVres), lâminas foliares verdes (MSLVres) e colmos verdes (MSCVres), assim como relações material vivo/material morto (MV/MMres) e folha/colmo (F/Cres), densidade populacional de perfilhos (DPP) e índice de área foliar residual (IAFres).

Médias na mesma linha, seguidas de letras iguais, não diferem $(P>0,05)$ pelo teste Tukey.

Modelo da equação de regressão escolhido com base na significância dos coeficientes linear e quadrático, utilizando-se o teste "t", de Student, a 10\% de probabilidade.

Tabela 7 - Efeito dos ciclos de pastejo sobre os componentes da biomassa pós-pastejo do capim-tanzânia sob lotação rotativa com quatro níveis de suplementação concentrada

\begin{tabular}{|c|c|c|c|c|c|c|}
\hline \multirow[t]{2}{*}{ Item } & \multicolumn{4}{|c|}{ Ciclo de pastejo } & \multirow[t]{2}{*}{ Média } & \multirow[t]{2}{*}{$\mathrm{CV}(\%)$} \\
\hline & 1 & 2 & 3 & 4 & & \\
\hline ALTres $(\mathrm{cm})$ & $28,38 \mathrm{a}$ & $28,40 \mathrm{a}$ & $28,47 \mathrm{a}$ & $28,45 \mathrm{a}$ & 28,42 & 1,01 \\
\hline MSFTres (kg/ha) & $6.330 \mathrm{a}$ & $6.473 \mathrm{a}$ & $5.557 \mathrm{a}$ & $6.125 \mathrm{a}$ & 6.121 & 14,17 \\
\hline MSFMres (kg/ha) & $2.484 \mathrm{a}$ & $2.174 \mathrm{a}$ & $2.253 \mathrm{a}$ & $2.393 \mathrm{a}$ & 2.326 & 19,94 \\
\hline MSFVres (kg/ha) & $3.200 \mathrm{a}$ & $3.557 \mathrm{a}$ & $3.304 \mathrm{a}$ & $3.797 \mathrm{a}$ & 3.465 & 8,96 \\
\hline MV/MMres & $1,30 \mathrm{a}$ & $1,58 \mathrm{a}$ & $1,71 \mathrm{a}$ & $1,84 \mathrm{a}$ & 1,61 & 18,39 \\
\hline MSLVres (kg/ha) & $1.217 \mathrm{~b}$ & $1.495 \mathrm{ab}$ & $1.564 \mathrm{ab}$ & $1.596 \mathrm{a}$ & 1.468 & 8,46 \\
\hline IAFres & - & $2,27 \mathrm{a}$ & $2,35 \mathrm{a}$ & $1,98 \mathrm{a}$ & 2,20 & 12,30 \\
\hline MSCVres (kg/ha) & $1.946 \mathrm{a}$ & $2.059 \mathrm{a}$ & $1.738 \mathrm{a}$ & $2.201 \mathrm{a}$ & 1.986 & 13,00 \\
\hline F/Cres & $0,68 b$ & $0,81 \mathrm{ab}$ & $0,92 \mathrm{a}$ & $0,78 \mathrm{ab}$ & 0,80 & 9,43 \\
\hline DPP (perfilhos $\left./ \mathrm{m}^{2}\right)$ & $553 \mathrm{ab}$ & $504 b$ & $5.45 \mathrm{ab}$ & $591 \mathrm{a}$ & 548 & 10,58 \\
\hline
\end{tabular}

Altura média residual (ALTres), massas secas de forragem total (MSFTres), de forragem morta (MSFMres), forragem verde (MSFVres), lâminas foliares verdes (MSLVres) e colmos verdes (MSCVres), assim como relações material vivo/material morto (MV/MMres) e folha/colmo (F/Cres), densidade populacional de perfilhos (DPP) e índice de área foliar residual (IAFres);

Médias na mesma linha, seguidas de letras iguais, não diferem $(P>0,05)$ pelo teste Tukey. 
$5,0 \mathrm{~cm}$ versus $15,0 \mathrm{~cm}$ do referido autor. Além disso, a pressão de pastejo exercida pelos ovinos suplementados sobre o capim acarretou hábito de crescimento mais prostrado, acarretando massa de forragem residual superior àquela relatada por Silva (2004), ainda que para a mesma altura de resíduo do pasto $(28,0 \mathrm{~cm})$.

Embora de forma indireta, Cecato et al. (2001) relataram que a quantidade de forragem morta tem grande relevância na produção animal, face à contribuição da atividade microbiana na decomposição da matéria orgânica para a reciclagem de nutrientes no solo, tornando essencial sua mineralização nas camadas superficiais do solo. A elevada MSFTres observada nesta pesquisa deveu-se principalmente à alta MSFMres e massa seca de colmo verde residual (MSCVres), devido à baixa altura de corte para a amostragem da forragem.

A massa seca de forragem verde residual (MSFVres) do pasto com os ovinos não-suplementados $(3.727 \mathrm{~kg} / \mathrm{ha})$ não diferiu $(\mathrm{P}>0,05)$ daquelas dos níveis de $0,6 \%$ (3.453 kg/ha) e 1,8\% PV (3.614 kg/ha), porém o pasto do nível de suplementação de $0,0 \% \mathrm{PV}$ apresentou MSFVres superior $(\mathrm{P}<0,05)$ àquela do pasto sob nível de $1,2 \% \mathrm{PV}$, com $3.065 \mathrm{~kg} / \mathrm{ha}$.

Houve efeito quadrático $(\mathrm{P}<0,10)$ dos níveis de suplementação sobre a MSFVres do pasto (Tabela 6), estimada em 3.779 e $3.562 \mathrm{~kg} / \mathrm{ha}$ do pasto com ovinos nãosuplementados e suplementados no nível de 1,8\% PV, respectivamente, e mínimo estimado de $3.201 \mathrm{~kg} / \mathrm{ha}$ com $1,01 \%$ de suplementação. Isto demonstra a possível ocorrência de efeito aditivo, com os animais exercendo maior intensidade de pastejo sobre a estrutura do pasto até o nível de $1,01 \%$ de suplementação e, em seguida, efeito substitutivo, reduzindo a intensidade de pastejo.

Não foram observadas diferenças $(\mathrm{P}>0,05)$ entre os ciclos, com MSFVres média de $3.465 \mathrm{~kg} / \mathrm{ha}$ (Tabela 7). Este resultado era esperado, uma vez que a pesquisa foi dimensionada para atingir a mesma pressão de pastejo em todo o período experimental. Brâncio et al. (2003), trabalhando com três cultivares do gênero Panicum, obtiveram MSFV residuais próximas de $2.700,1.700$ e $3.400 \mathrm{~kg} / \mathrm{ha}$ para os cultivares Tanzânia, Mombaça e Massai, respectivamente, com período de descanso de 35 dias, sendo inferiores aos valores encontrados neste experimento.

Não houve efeito dos níveis de suplementação $(P>0,10)$, nem entre níveis de suplementação $(\mathrm{P}>0,05)$ e nem entre ciclos de pastejo $(\mathrm{P}>0,05)$ para relação material vivo/material morto residual (MV/MMres), ficando com média igual a 1,61 (Tabelas 6 e 7).

A massa seca de lâminas foliares verdes residuais (MSLVres) do pasto cujos ovinos foram suplementados a
$0,6 \%$ PV $(1.273 \mathrm{~kg} / \mathrm{ha})$ foi semelhante $(\mathrm{P}>0,05)$ à do nível de $0,0 \% \mathrm{PV}(1.461 \mathrm{~kg} / \mathrm{ha})$, porém inferior $(\mathrm{P}<0,05)$ à obtida em pastos com níveis de suplementação de 1,2 e 1,8\% PV, com 1.534 e $1.605 \mathrm{~kg} / \mathrm{ha}$, respectivamente (Tabela 6). No tocante ao efeito dos níveis de suplementação sobre o índice de área foliar residual (IAFres), observou-se que o pasto dos ovinos suplementados com $1,8 \% \mathrm{PV}(2,70)$ foi semelhante $(\mathrm{P}>0,05)$ ao do nível de $1,2 \% \mathrm{PV}(2,23)$, porém superior $(\mathrm{P}<0,05)$ aos demais (Tabela 6$)$.

$O$ estudo da equação de regressão mostrou efeito quadrático $(\mathrm{P}<0,10)$ dos níveis crescentes de suplementação sobre a MSLVres e o IAFres do pasto (Tabela 6). Estimaram-se MSLVres de 1.429 e $1.636 \mathrm{~kg} / \mathrm{h}$ a nos pastos dos ovinos nãosuplementados e suplementados no nível de 1,8\% PV, respectivamente, e mínimo estimado de $1.368 \mathrm{~kg} / \mathrm{ha}$ com $0,58 \%$ de suplementação. O mesmo foi verificado com o IAF residual, mostrando que ambos são correlacionados positivamente. O IAF residual foi estimado em 2,03 e 2,71 nos pastos dos ovinos suplementados com níveis de 0,0 e 1,8\% $\mathrm{PV}$, respectivamente, e mínimo estimado de 1,89 com $0,52 \%$ de suplementação. Não foram observadas diferenças $(\mathrm{P}>0,05)$ entre ciclos para a variável IAFres, ficando com média de 2,20 (Tabela 7).

Embora não tenha havido diferença no IAFres entre os ciclos, a tendência $(\mathrm{P} \leq 0,17)$ de redução do ciclo 3 para o 4 reforça o risco de se manejar o pasto com base na sua altura. A elevação na taxa de alongamento das hastes (TAlH) (dados não apresentados) do ciclo 2 para o 4 (18,09 a 20,40 cm) fez com que, para uma mesma altura de resíduo pós-pastejo, restasse menor área foliar no pasto que teve suas hastes alongadas (principalmente no último ciclo), elevando o dossel e a proporção de folhas removidas durante o pastejo.

Quanto ao efeito de ciclos sobre a MSLVres (Tabela 7), observou-se que o ciclo $4(1.596 \mathrm{~kg} / \mathrm{ha})$ foi superior $(\mathrm{P}<0,05)$ ao ciclo $1(1.217 \mathrm{~kg} / \mathrm{ha})$, não diferindo $(\mathrm{P}>0,05)$ dos demais. As maiores MSLVres e IAFres nos pastos cujos ovinos receberam 1,2 e 1,8\% de suplementação, especialmente neste último, são indicativo de ocorrência de efeito substitutivo do suplemento, pelo menos no maior nível de suplementação.

A MSLVres e o IAFres tem papel fundamental na rebrotação do pasto, pois a área foliar verde remanescente após o pastejo é diretamente proporcional à taxa de fotossíntese líquida do pasto (Gomide et al., 2002). Além disso, quanto maior a proporção de lâminas foliares remanescentes, menor é a necessidade da planta em mobilizar suas reservas orgânicas para retomar seu crescimento. Silva (2004), trabalhando com o mesmo cultivar sob períodos de descansos de 1,5;2,5 e 3,5 F/P, relatou MSLV residual de 
720,818 e $695 \mathrm{~kg} / \mathrm{ha}$, respectivamente, sendo inferiores aos verificados neste experimento.

A massa seca de colmo verde residual (MSCVres) do pasto com os ovinos suplementados a 1,2\% PV $(1.531 \mathrm{~kg} / \mathrm{ha})$ foi semelhante $(\mathrm{P}>0,05)$ à do nível de $1,8 \% \mathrm{PV}$ $(2.007 \mathrm{~kg} / \mathrm{ha})$, porém foi inferior $(\mathrm{P}<0,05)$ aos pastos dos níveis de suplementação de 0,0 e $0,6 \%$ PV, com 2.228 e $2.178 \mathrm{~kg} / \mathrm{ha}$, respectivamente. Houve ainda efeito quadrático $(\mathrm{P}<0,10)$ dos níveis de suplementação sobre a MSCVres, com mínimo estimado de $1.789 \mathrm{~kg} / \mathrm{ha}$, com $1,2 \%$ de suplementação (Tabela 6). Estimando-se o ponto de mínimo da MSLVres, IAFres e MSCVres de 0,58; 0,52 e 1,2\% PV, respectivamente, sugere-se que o efeito substitutivo tenha sido iniciado neste intervalo $(0,52$ a $1,2 \% \mathrm{PV})$.

Quanto ao efeito de ciclos (Tabela 5), não foi observada diferença $(\mathrm{P}>0,05)$ para MSCVres, ficando com média de $1.986 \mathrm{~kg} / \mathrm{ha}$, apesar de ter havido tendência $(\mathrm{P} \leq 0,23)$ no último ciclo, reflexo do aumento progressivo na TAlH $(0,09$ a $0,13 \mathrm{~cm} /$ perfilho $\mathrm{x}$ dia) e na altura do pseudocolmo $(16,48$ e 20,40 cm/dia-ciclos 1 e 4, respectivamente), com os ciclos de pastejo (dados não apresentados).

Quanto ao efeito dos níveis de suplementação sobre a relação folha/colmo residual (F/Cres) (Tabela 6), não foram observadas diferenças $(\mathrm{P}>0,05)$ entre os pastos dos ovinos suplementados com 0,0 e $0,6 \% \mathrm{PV}$, com média de 0,65 , entretanto foram inferiores $(\mathrm{P}<0,05)$ aos demais.

Constata-se que, embora a massa de colmo tenha aumentado no último nível de suplementação, a massa de lâmina foliar elevou-se ainda mais, ampliando a relação F/Cres, não comprometendo a estrutura da pastagem. Esse aumento na relação F/Cres também sugere a ocorrência do efeito substitutivo nos maiores níveis de suplementação, visto que a fração folha é aquela preferencialmente selecionada pelo animal em pastejo. Quanto ao efeito de ciclos, foi observada diferença $(\mathrm{P}>0,05)$ entre os ciclos 3 e 1 , porém ambos não diferiram dos demais (Tabela 7). As relações MV/MMres e F/Cres foram reduzidas em relação ao prépastejo, o que também foi relatado por Silva (2004), devendo-se ao fato de os animais, durante o pastejo em cada piquete, terem preferência por lâminas foliares verdes.

Quanto à densidade populacional de perfilhos (DPP), não foi observado efeito $(\mathrm{P}>0,10)$ dos níveis de suplementação e nem entre níveis de suplementação $(\mathrm{P}>0,05)$, apresentando média igual a 548 perfilhos $/ \mathrm{m}^{2}$ (Tabela 6). Observou-se que o ciclo 4 foi superior $(\mathrm{P}<0,05)$ ao ciclo 2, porém semelhante $(\mathrm{P}>0,05)$ aos demais (Tabela 7). Apesar de haver o receio de que o nível de suplementação de $1,8 \%$ PV cause comprometimento na estrutura da pastagem, devido ao maior número de animais e ao maior peso dos mesmos, não se observaram indícios de degradação, uma vez que a DPP não foi alterada $(\mathrm{P}>0,05)$ com os níveis de suplementação.

A DPP observada nesta pesquisa foi superior àquela relatada por Silva (2004), trabalhando com o mesmo cultivar sob três PD (1,5; 2,5 e 3,5 F/P), que obteve DPP de 431, 472 e 378 perfilhos $/ \mathrm{m}^{2}$, respectivamente. Este resultado não era esperado, visto que neste experimento o IAF residual médio de 2,20 foi maior que o do referido autor $(1,0)$, conferindo melhor condição de rebrotação, podendo chegar mais rapidamente aos IAFs que desencadeassem sombreamento mútuo, inibindo o perfilhamento. Infere-se que o hábito de crescimento mais prostrado relatado nesta pesquisa refletiu maior IAF para a mesma altura residual do pasto adotada, inibindo possivelmente a brotação de novas gemas. Por outro lado, é possível que tenha havido compensação com a quebra da dominância apical de muitos perfilhos decapitados, por ocasião da maior intensidade de pastejo observada, estimulando a brotação de gemas basilares e axilares, e, conseqüentemente, o perfilhamento.

Costa et al. (1992), trabalhando com os cultivares Colonião e Tobiatã, relataram DPPs de 526e 394 perfilhos $/ \mathrm{m}^{2}$, respectivamente, ao passo que Canto et al. (2002), trabalhando com diferentes alturas de capim-tanzânia no Noroeste do Paraná, citaram DPP de 625 perfilhos $/ \mathrm{m}^{2}$ quando submetida a cortes de $55,8 \mathrm{~cm}$. Apesar de as condições climáticas deste experimento terem sido ideais para obtenção de altas produtividades, as elevadas DPPs relatadas por esses autores deveu-se principalmente às elevadas doses de nitrogênio aplicadas (média de 50,0 kg N/ha x ciclo), enquanto neste experimento a dose aplicada foi de $35,0 \mathrm{~kg} \mathrm{~N} / \mathrm{ha}$ x ciclo.

\section{Conclusões}

Os níveis crescentes de suplementação exerceram pouca influência sobre a estrutura do pasto, mantendo os componentes da biomassa dentro de níveis aceitáveis. A massa de colmo residual sugeriu maior grau de utilização do pasto pelos animais suplementados até o nível de 1,2\% PV, invertendo a resposta daí em diante.

\section{Literatura Citada}

ANSLOW, R.C. The rate of appearance of leaves on tillers of the gramineae. Herbage Abstracts, v.36, n.3, p.149-155, 1966. BRÂNCIO, P.A.; EUCLIDES, V.P.B.; NASCIMENTO JR., D. et al. Avaliação de três cultivares de Panicum maximum Jacq. sob pastejo: disponibilidade de forragem, altura do resíduo póspastejo, e participação de folhas, colmos e material morto.

Revista Brasileira de Zootecnia, v.32, n.1, p.55-63, 2003. BROUGHAM, R.W. Effect of intensity of defoliation on regrowth of pasture. Australian Journal of Agricultural Research, v.7, n.2, p. 377-387, 1956 
CÂNDIDO, M.J.D. Morfofisiologia e crescimento do dossel e desempenho animal em Panicum maximum cv. Mombaça sob lotação intermitente com três períodos de descanso. Viçosa, MG: Universidade Federal de Viçosa, 2003. 134p. 2003. Tese (Doutorado em Zootecnia) - Universidade Federal de Viçosa, 2003.

CANTO, M.W.; CECATO, U.; AlmeidA JR., J. et al. Produção animal no inverno em capim Tanzânia diferido no outono e manejado em diferentes alturas de pasto. Revista Brasileira de Zootecnia, v.31, n.4, p.1624-1633, 2002.

CANTO, M.W.; CECATO, U.; PETERNELli, M. et al. Efeito da altura do capim Tanzânia diferido nas características da pastagem no período do inverno. Revista Brasileira de Zootecnia, v.30, n.4, p.1186-1193, 2001.

CARDOSO, E.G. Suplementação de bovinos de corte em pastejo (semiconfinamento). In: SIMPÓSIO SOBRE PRODUÇÃO ANIMAL: confinamento de bovinos, 9., 1997, Piracicaba. Anais... Piracicaba: Fundação de Estudos Agrários Luiz de Queiroz, 1997. p.97-120.

CARVALHO, P.C.F.; GENRO, T.C.M.; GONÇALVES, E.N. et al. A estrutura do pasto como conceito de manejo: reflexos sobre o consumo e a produtividade. In: SIMPÓSIO DE VOLUMOSOS NA PRODUÇÃO DE RUMINANTES, 2., 2005, Jaboticabal. Anais... Jaboticabal: Funep, 2005. p.107-124.

CARVALHO, P.C.F.; OLIVEIRA, J.O.R.; PONTES, L.S. et al. Características de carcaça de cordeiros em pastagem de azevém manejada em diferentes alturas. Pesquisa Agropecuária Brasileira, v.41, n.7, p.1193-1198, 2006.

CARVALHO, P.C.F.; RIBEIRO FILHO, H.M.N.; POLI, C.H.E.C. et al. A importância da estrutura da pastagem na seleção de dietas pelo animal em pastejo. In: SIMPÓSIO SOBRE A PRODUÇÃO ANIMAL NA VISÃO DOS BRASILEIROS/ REUNIÃO DA SOCIEDADE BRASILEIRA DE ZOOTECNIA, 38., 2001, Piracicaba. Anais... Piracicaba: Sociedade Brasileira de Zootecnia, 2001. p.853-871.

CECATO, U.; CASTRO, C.R.C.; CANTO, M.W. et al. Perdas de forragem em capim Tanzânia (Panicum maximum Jacq. cv.Tanzânia-1) manejado sob diferentes alturas sob pastejo. Revista Brasileira de Zootecnia, v.30, n.2, p.295-301, 2001.

CECATO, U.; MACHADO, A.O.; MARTINS, E.N. et al. Avaliação da produção e de algumas características da rebrota de cultivares e acessos de Panicum maximum Jacq. sob duas alturas de corte. Revista Brasileira de Zootecnia, v.29, n.3, p.660-668, 2000.

COMISSÃO DE FERTILIDADE DO SOLO DO ESTADO DE MINAS Gerais - CFSEME. Recomendações para uso de corretivos e fertilizantes em Minas Gerais - $5^{\mathbf{a}}$ Aproximação. Viçosa, MG: Universidade Federal de Viçosa, 1999. 359p.

COSTA, C.; FAVORETTO, V.; MALHEIROS, E.B. Estudo da variação na estrutura da vegetação de duas cultivares de Panicum maximum Jacq. (Colonião e Tobiatã) submetidas a diferentes tipos de manejo. Pesquisa Agropecuária Brasileira, v.27, n.1, p.131-142, 1992.
EMPRESA BRASILEIRA DE PESQUISA AGROPECUÁRIA EMBRAPA. Sistema brasileiro de classificação dos solos. Brasília: CNPS, 1999. 412p.

GOMIDE, J.A.; GOMIDE, C.A.M. Morfogênese de cultivares de Panicum maximum Jacq. Revista Brasileira de Zootecnia, v. 29, n.2, p.341-348, 2000 .

GOMIDE, C.A.M.; GOMIDE, J.A.; HUAMAN, C.A.M. et al. Fotossíntese, reservas orgânicas e rebrota do capim-mombaça (Panicum maximum Jacq.) sob diferentes intensidades de desfolha do perfilho principal. Revista Brasileira de Zootecnia, v.31, n.6, p.2165-2175, 2002.

GOMIDE, J.A. Fisiologia e manejo de plantas forrageiras. Revista da Sociedade Brasileira de Zootecnia, v.2, n.1, p.17-25, 1973.

HODGSON, J. Grazing management: science into practice. Harlow: Longman Scientific \& Technical, 1990. 203p.

LEMAIRE, G. Ecophysiology of grasslands: dynamics aspects of plant population in grazed swards. In: INTERNATIONAL GRASSLAND CONGRESS, 19., 2001, São Pedro. Proceedings... São Pedro: 2001. (CD-ROM).

MINSON, D.J. Forage in ruminant nutrition. London: Academic Press, 1990. 483p.

NABINGER, C. Manejo da desfolha. In: SIMPÓSIO SOBRE MANEJO DE PASTAGEM: Inovações tecnológicas no manejo de pastagem, 19., 2002, Piracicaba. Anais... Piracicaba: Fundação de Estudos Agrários Luiz de Queiroz, 2002. p.133-158.

NATIONAL RESEARCH COUNCIL - NRC. Nutrient requirements of sheep. New York: National Academy Press, 1985. 99p.

NATIONAL RESEARCH COUNCIL - NRC. Nutrient requirements of dairy cattle. New York: National Academy Press, 2001. 381p.

PINTO, J.C.; GOMIDE, J.A.; MAESTRI, M. Produção de matéria seca e relação folha:caule de gramíneas forrageiras tropicais, cultivadas em vasos, com duas doses de nitrogênio. Revista da Sociedade Brasileira de Zootecnia, v.23, n.3, p.313-326, 1994.

STATISTICAL ANALYSIS SYSTEM - SAS. SAS system for windows. Version 8.0. Cary: 1999. (CD ROM).

SILVA, R.G. Morfofisiologia do dossel e desempenho produtivo de ovinos em Panicum maximum (Jacq.) cv. Tanzânia sob três períodos de descanso. Fortaleza: Universidade Federal do Ceará, 2004. 114p. Dissertação (Mestrado em Zootecnia) Universidade Federal do Ceará, 2004.

SILVA, D.J.; QUEIROZ, A.C. Análise de alimentos: métodos químicos e biológicos. Viçosa, MG: Editora UFV, 2002. 235p.

SNIFFEN, C.J.; O' CONNOR, J.D.; van SOEST, P.J. et al. A net carbohydrate and protein system for a evaluating cattle diets: II. Carbohydrate and protein availability. Journal of Dairy Science, v.70, p.3562-3577, 1992.

UEBElE, M.C. Padrões demográficos de perfilhamento e produção de forragem em pastos de capim-mombaça submetidos a regimes de lotação intermitente. Piracicaba: Escola Superior de Agricultura Luiz de Queiroz, 2002. 83p. Dissertação (Mestrado em Agronomia) - Escola Superior de Agricultura Luiz de Queiroz, 2002. 